Reviewing a $10 \mathrm{~kg}$, three-volume textbook with more than 4000 pages is not easy. One could read the whole shebang cover to cover! Alternatively, one can dip into it as a practical text for a clinical neurologist, and, in this way, find that it does exactly what it sets out to do. One frustration with the softbound version is the inaccuracy of the index. Topics are often a few pages from where they should be. This is only a small discrepancy, but it can prove to be slightly exasperating. It is the sort of error that may have occurred in transcription from hardbound to soft.

Beautifully illustrated, the Oxford textbook of medicine is a "must have" for all neurologists. The hardbound version will sit better (and look better) on your shelf and probably be more exact in its index. Get someone to buy it for you.

S Edwards

\section{Stroke treatment and prevention: an evidence-based approach}

Edited by Graeme J Hankey. Published by Cambridge University Press, Cambridge, 2005 , $£ 80.00$ (hardcover), pp 514. ISBN 0-52182719-1

Stroke treatment and prevention: an evidence-based approach provides an up-to-date review of all major aspects of treatment of acute stroke and secondary prevention after transient ischaemic attack or stroke, including primary intracerebral haemorrhage and subarachnoid haemorrhage. There are at least five reasons why this book will be of day-to-day practical use to neurologists and other physicians who treat patients with cerebrovascular disease. Firstly, all the evidence from randomised controlled trials of the effectiveness of each treatment option is presented in a clear and concise format. No other book on stroke brings together such a wealth of data on the risks and benefits of treatments for such a broad range of clinical indications. Secondly, and more importantly, in addition to the Forest plots, the author gives insightful commentaries on the implications of the data for treatment decisions in routine clinical practice. It is abundantly clear to the reader that the author is an experienced clinician who understands the complexities of decision making in the real world. Indeed, the value of this book is as much in the clinical insight as it is in the rigorous documentation of the evidence base itself. Thirdly, evidence is also reviewed, where available, on how the effects of treatments differ between important subgroups and on how clinicians can target treatments, such as carotid endarterectomy and thrombolysis, most effectively. Fourthly, as a consequence of the above, the book is a practical how to manual, as well as a rigorous scientific review. Finally, the author does not neglect those conditions for which there are no data from randomised trials to guide treatment decisions, such as arterial dissection, primary angiitis of the central nervous system and prevention of stroke in infective endocarditis.

All relevant observational data are reviewed and sensible treatment strategies are suggested. All in all, the fusion of data from randomised trials with an understanding of the pathophysiology and natural history of disease and an appreciation of practical realities make this book an unusually helpful exposition of evidencebased medicine.

P M Rothwell

\section{Neurological practice - an Indian perspective}

Edited by Noshir $\mathrm{H}$ Wadia. Published by Elsevier, New Delhi, 2005, £17 (hardcover), pp 694. ISBN 81-8147-549-6

Neurological practice - an Indian perspective is a multiauthor textbook that gives an impressive insight into past and contemporary Indian neurology. It is indeed befitting that this book is edited by Noshir Wadia, who is the founder of contemporary Indian neurology. His contribution is felt throughout the book (coauthor in 14 of the 32 chapters) and despite the multiple authors the book has a uniform, easy narrative style. The chapter subheadings accurately reflect the current neurological problems affecting the Indian and South East Asian population. The 11 chapters in the section on infections indicate, somewhat dishearteningly, that infection remains the most common cause of neurological disease in the region. The chapter on neurotuberculosis is a must read for neurologists everywhere as tuberculosis has become more widespread, and Indian neurologists have decades of experience in treating this. There are chapters on leprosy, poliomyelitis and subacute panencephalitis, conditions long forgotten in the West and thankfully on the decline in India. Two chapters in this section are outstanding, one on an adult form of polio associated with acute haemorrhagic conjunctivitis related to enterovirus 7 and the other is on neurocysticercosis, which surprisingly occurs in a predominantly vegetarian country, and is related to poor hygienic practice in growing fruit and vegetables. The brain images of a patient with millions of live cysticercii, referred to as the "starry starry night appearance" (a la Van Gogh), are unforgettable, as are the images of leg muscles laden with cysticercii. Practical tips on taking plain $\mathrm{x}$ rays of muscles when looking for calcified cysticerci as screening tests and management issues, including the danger of treating patients having high cysticerci loads with praziquantel, are the highlights of this chapter. Other sections include chapters on epilepsy, vascular disease, movement disorders, environmental disorders, etc, as expected in standard neurology textbooks, but with descriptions of certain conditions fairly unique to India. Examples of these conditions include hot water epilepsy, a form of reflex epilepsy induced by hot water on the head, Madras motor neuron disease, a benign form of amyotrophic lateral sclerosis and monomelic amyotrophy. Other exotica include snake poisoning and descriptions about lathyrism, a pure spastic condition caused by a lentil (lathyrus sativus) consumed in the drought season, which has a glutamate receptor neurotoxin. Endemic fluorosis, the result of excessive fluoride in ground water and causing spinal cord syndromes, is still seen in certain parts of India. Lastly, there is a wonderful account of a familial ataxia associated with slow eye movements, which was called the Wadia-Swami syndrome until the finding of the SCA-2 gene, the most common form in India.

Who should read or acquire this book? In India it has a rightful place in every medical library, and will be read by every neurologist and trainee. As Indians constitute the second largest population and live in all parts of the world, however, this book has relevance to practising neurologists everywhere.

K P Bhatia

\section{CORRECTIONS}

doi: 10.1136/jnnp.2005.067777corr I

J Williams, C Lawthom, F D Dunstan, et al. Variability of antiepileptic medication taking behaviour in sudden unexplained death in epilepsy: hair analysis at autopsy ( $J$ Neurol Neurosurg Psychiatry 2006:77:481-4). In figure 1 the data point at 0,0 , which currently appears in the "non-SUDEP" group, should appear instead at point 0,0 in the "SUDEP" group.

\section{doi: 10.1136/jnnp.2005.077297corr 1}

S Okawa, M Sugawara, S Watanabe, et al. A novel sacsin mutation in a Japanese woman showing clinical uniformity of autosomal recessive spastic ataxia of CharlevoixSaguenay (J Neurol Neurosurg Psychiatry 2006;77:280-2). The last author of this letter is I Toyoshima and not T Imota, as published. We apologise for this error.

doi: 10.1136/jnnp.2006.089698corr 1 C Stapf. Endovascular management of unruptured intracranial aneurysms: the dawn of a multidisciplinary treatment paradigm (J Neurol Neurosurg Psychiatry 2006;77:el). This editorial commentary should have been published alongside its linked paper in the print journal, but owing to human error it was not. Therefore, the commentary has been published as an electronic page in this issue. We apologise for the error.

doi: 10.1136/jnnp.2005.078311corr l

P Scheltens. Subcortical ischaemic vascular dementia: a separate disease entity? (J Neurol Neurosurg Psychiatry 2006;77). This editorial commentary should have been published alongside its linked paper in the print journal, but owing to human error it was not. The commentary can be viewed online at http:/ jnnp.bmjjournals.com/cgi/data/77/1/28/DC1/1. We apologise for the error.

doi: 10.1136/jnnp.2005.079822corr l

T Fukushima, M Shirota, T Yonemitsu, et al. Spinal endoscopic biopsy in the diagnosis of central nervous system neurosarcoidosis $(J$ Neurol Neurosurg Psychiatry 2006;77:702). The authors' names, K Yamada and M Tannno, were published incorrectly. The correct author names are $\mathrm{Y}$ Yamada and $\mathrm{M}$ Tanno. In addition the correct order of the authors is: $\mathrm{T}$ Fukushima, M Shirota, T Yonemitsu, T Yamaguchi, Y Yamada, M Tanno, M Waragai. 